Revista de la red interuniversitaria de estudios sobre las literaturas rioplatenses contemporáneas en Francia

Hors-série | 2019

Ricardo Piglia: Cierta idea de literatura

\title{
Traiciones en El camino de Ida
}

\section{Luis Othoniel Rosa}

\section{OpenEdition}

\section{Journals}

Edición electrónica

URL: http://journals.openedition.org/lirico/7670

DOI: 10.4000/lirico.7670

ISSN: 2262-8339

Editor

Réseau interuniversitaire d'étude des littératures contemporaines du Río de la Plata

\section{REFERENCIA ELECTRÓNICA}

Luis Othoniel Rosa, « Traiciones en El camino de Ida », Cuadernos LIRICO [En línea], Horssérie | 2019, Puesto en línea el 27 febrero 2019, consultado el 10 mayo 2019. URL : http:// journals.openedition.org/lirico/7670 ; DOI : 10.4000/lirico.7670

Este documento fue generado automáticamente el 10 mayo 2019.

\section{c) 89}

Cuadernos LIRICO está distribuido bajo una Licencia Creative Commons Atribución-NoComercialSinDerivar 4.0 Internacional. 


\title{
Traiciones en El camino de Ida ${ }^{1}$
}

\author{
Luis Othoniel Rosa
}

1

En su última novela, ominosamente titulada El camino de Ida, Ricardo Piglia elabora varios temas que recorren toda su obra: el anarquismo, la crítica al capitalismo y la conflictiva relación entre el crítico literario y la institución universitaria. Son tres temas que en mayor o menor medida aparecen a lo largo de su obra pero que sólo en esta novela se convertirán en el tema principal. Y sin embargo, El camino de Ida frustra las expectativas del asiduo lector de su obra. Si el anarquismo en todas sus otras novelas aparecía como una práctica deseable tanto estética como políticamente, en El camino de Ida nos presenta un anarquismo aristocratizante y asesino. Si la crítica al capitalismo en su obra frecuentemente produce líneas de fuga para la creación de otras realidades y deseos que cuestionan la materia misma de la realidad y la mercantilización de los cuerpos (La ciudad ausente), la ficción del dinero (Plata quemada) y la industrialización (Blanco nocturno), en esta última novela la crítica explícita al capitalismo nos conduce a un anacronismo estéril y europeizante, casi como una obstinación decadente de un mundo premoderno que se resiste a morir. Por último, si el acto de la lectura obsesiva y la tertulia literaria producen las páginas más llenas de aura en el resto de la obra de Piglia, en El camino de Ida estos actos parecen completamente coartados por la torre de marfil universitaria, tan tecnócrata en sus ciencias como irrelevante en sus humanidades; la literatura se nos muestra como una mala fe en la que hasta hay que "matar para conseguir lectores". Para un autor como Piglia, tan obsesionado con los finales en la literatura (ver "Nuevas tesis sobre el cuento" (2006), cuyo argumento principal es sobre cómo los finales en la literatura cifran el sentido), este final de su obra novelística, este último camino de ida, fracasa en sorprendernos, en levantarnos de la silla como los finales en los cuentos de Borges. En tanto final de su obra novelística, El camino de Ida nos recuerda la desazón terrible al final de El juguete rabioso de Roberto Arlt, cuando los lectores nos sentimos traicionados porque resulta que el protagonista es un delator, un traidor, pues, de todos los deseos y rebeldías que hemos confiado en él a lo largo de la novela. 
2 Piglia escribe esta novela durante su última década en Princeton (2001-2011) y ese momento y lugar histórico es fundamental para entender la novela, tanto como resulta esperado para los que estamos acostumbrados a la manera secreta en la que Piglia cifra el presente histórico en sus ficciones: la dictadura en Respiración artificial, la transición neoliberal argentina en La ciudad ausente, las burbujas financieras y la corrupción política en Plata quemada, el conflicto con el campo argentino "anti-K" en Blanco nocturno. Escribe esta novela en Estados Unidos en años que inician con los ataques del 11 de septiembre y las interminables Guerras de Irak y Afganistán, que continúan con la singular crisis financiera del 2008 manufacturada por Wall Street, y que cierran con el surgimiento eufórico de movimientos "horizontales" anticapitalistas en todo el mundo que marcan una resistencia global bien organizada pero anti-institucional (muy diferente, pues, de la llamada "marea rosada") que, Piglia nos admite a muchos alumnos, está muy cerca de sus propias posiciones políticas de tendencia anarquista ${ }^{2}$. Entonces, ante ese presente histórico que parece tan propicio para la teoría del complot pigliana, para escribir una novela que articule utópicamente las maneras en que la ficción y la lectura obsesiva nos permiten modos de acción directa para complotar contra los poderosos (como de hecho lo hace nuestra novela favorita de Piglia, La ciudad ausente), nos ofrece lo contrario: una novela que parece dejarnos solos en una cabaña ermitaña sin nada más que hacer que leer las notas que una muerta escribe sobre una novela olvidada de Conrad.

¿Por qué? ¿Por qué Piglia nos deja este final tan descorazonador? La intención de este ensayo es contestar esa pregunta, y sin embargo, cierto miedo, cierto sentimiento de fraude (como el de Emilio Renzi con Ratliff en Prisión perpetua), cierta decepción, nos parece, evitará que terminemos de contestarla.

\section{2}

El camino de Ida es una "American novel", un saldo de cuentas que hace el autor con la tradición literaria norteamericana, el pago de una deuda a esa dicotomía tan inagotable que vemos en esa tradición entre literatura y experiencia ${ }^{3}$, y también un saldo de cuentas con la institución académica (veneno/remedio). Narrativamente, la novela se divide en tres partes. Primero, una etnografía muy crítica de la academia americana y su complicidad con el capitalismo, en la que Renzi tiene un affaire con la profesora Ida Brown, lectora de Conrad que guerrea contra la despolitización del postestructuralismo. Luego tenemos la novela policial. Ida es asesinada y el narrador se lanza en su tarea detectivesca. Por último, surge la figura monstruosa y sublime de Thomas Munk, anarcoterrorista que parece sacado de las novelas de Conrad, Chesterton o Arlt, que escribe un Manifiesto contra el capitalismo tecnológico y asesina a una serie de académicos precisamente para que los medios de información le presten atención a su manifiesto. Munk está basado en el famoso Unabomber, Theodor J. Kaczynski.

\section{3}

5 El camino de Ida parece una novela gemela de La ciudad ausente: ambas se organizan en torno a una amada muerta (la muerta Ida Brown de Renzi es una mala gemela de la Elena de Macedonio Fernández), ambas postulan formas tecnológicas anarquistas de manipular los sistemas de información y los medios con el fin de generar relatos que se infiltren en 
el sistema político y lo destruyan desde adentro (el Manifiesto contra el capitalismo tecnológico de Munk y la "máquina" de Mac), ambas cifran la intriga en la lectura minuciosa de textos decimonónicos (Conrad en una, Poe en la otra). Y sin embargo, son novelas que no podrían ser más disímiles. No sólo porque La ciudad ausente es un delirio eufórico de la ciencia ficción mientras que El camino de Ida es una larga melancolía realista y autobiográfica. Son novelas opuestas fundamentalmente porque la primera tiene un efecto revolucionario en el lector mientras que la segunda parece abocada con furia a destruir a todos los lectores ilusos que han creído que en la ficción y en la lectura obsesiva hay cualquier posibilidad de emancipación del ubicuo necrocapitalismo ${ }^{4}$ que nos aplasta. En más de un sentido, El camino de Ida, tanto formal como argumentativamente, parece estar construida para destruir todas las posibilidades revolucionarias de la literatura que La ciudad ausente construyó.

6 La paranoia es el artefacto predilecto del pensamiento pigliano ${ }^{5}$. Las figuras delirantes de los y las paranoicas en sus textos, más que revelar o denunciar la persecución estatal, exploran la relación entre narración y poder, muestran los pliegues entre estas dos categorías. El poder en la modernidad tiene una estructura narrativa fija pero siempre creciente, una estructura tan clásica como el imperialismo mismo, pero siempre capaz de incorporar un nuevo territorio. Entonces, si el poder se construye como una ficción fija en Piglia, la manera de confrontarse con él es también narrativa; ante la imposición de una narrativa fija, la diseminación de unas narrativas plurales y desestabilizadoras. El lector paranoico, que se abandona a la lectura no por placer o por ocio sino por una necesidad irresistible de descifrar la maquinaria del poder, actúa una pulsión de conocimiento que lo convertirá en el profeta de unas formas del futuro, tan distópicas como utópicas, pero siempre proféticas. La paranoia también es el artefacto, el motor del pensamiento, en $\mathrm{El}$ camino de Ida, pero con una vuelta de tuerca que desnuda a la paranoia de su utilidad profética. Como si esa última novela nos quisiera decir que a veces los paranoicos no son profetas, que a veces los paranoicos son simplemente paranoicos, que por ahí todo este fetiche que tenemos con los locos es el producto terrible del aburrimiento de la clase educada, tan indiferente.

\section{4}

7 En la obra de Piglia publicada hasta ahora, encontramos por primera vez el germen explícito de El camino de Ida en una divertida y curiosa conversación pública que tiene con Roberto Bolaño. Ambos en ese momento son las figuras claves de la prestigiosa editorial Anagrama. Allí, Piglia le cuenta a Bolaño que está leyendo una biografía de Hudson (que es el tema del seminario que enseña Renzi en la ficcional Taylor University) escrita por una traductora del ruso llamada Constance Garnett (que en la novela se convertirá en Nina, una vieja rusa feminista con la que Renzi tiene las mejores conversaciones literarias de la novela). Es una conversación llena de respeto y curiosidad libresca, y por momentos es un tanto tensa, ya que Piglia y Bolaño, a pesar de compartir muchas lecturas y venir, aparentemente, de una misma tradición literaria, sienten sus poéticas encontradas. La última novela de Bolaño, 2666, comparte algunas temáticas con El camino de Ida: ambas novelas trabajan el motivo de "salir de la biblioteca", de ir de los libros a la realidad, de hacer delirar a la universidad; ambas son policiales en las que se investiga a un intelectual descarrilado por la violencia del presente (Munk y Archimboldi); ambas se desarrollan en un mundo en el que el capitalismo como máquina de muerte parece haberse tragado al 
mundo; ambas construyen un alter ego del autor (Renzi y Amalfitano) que parece intelectualmente derrotado ante una realidad que lo supera. El crítico Francisco Carrillo, quien fue uno de los muchos alumnos que nos formamos en los seminarios doctorales de Piglia en Princeton, argumenta en un libro sobre Bolaño (2014) que mientras que Los detectives salvajes es una novela llena de euforia política, de revolucionar las maneras de vivir "sin timón y en el delirio", 2666 es una novela de la derrota de ese mismo proyecto estético-político que se construye en la obra anterior. Las similitudes acá no pueden ser ignoradas. Los dos grandes novelistas latinoamericanos que más han influenciado a los escritores del siglo XXI del continente parecen tener vidas literarias paralelas. Ambos construyen una poética muy contagiosa cuyo gran logro es devolverle el "aura" (en el sentido que le da Walter Benjamin a este concepto, como una forma contra la alienación del capitalismo tecnológico) a la figura del lector obsesivo. El "éxito" de sus obras está ahí, porque logran contagiarnos con ese personaje del lector obsesivo en los años noventa y dos mil, décadas marcadas por una despolitización terrible tras la caída de la alternativa comunista, por el neoliberalismo económico y por el posmodernismo cultural ${ }^{6}$. Es una gran hazaña. Por supuesto, ese personaje del lector voraz lo "plagian" de Borges. Sin embargo, lo mejoran mucho por dos razones. Primero, porque si para los personajes lectores de Borges la experiencia siempre es una imposibilidad deseada ("El sur"), como si la biblioteca estuviera separada de la vida, los personajes lectores de Piglia y Bolaño habitan nuestro mundo y son capaces de tener experiencias en un mundo capitalista que parece negárnosla. Segundo, porque politizan y radicalizan a ese personaje borgeano (desde la izquierda).

Borges nos enseña cómo la ficción en vez de reflejar la sociedad, más bien la organiza, y el buen lector es aquél que luego de leer un libro se percata de que el Poder en nuestra sociedad se organiza como una ficción ("La lotería en Babilonia") y que la realidad misma puede ser descifrada de la manera en que desciframos un libro ("La biblioteca de Babel", "El Aleph", “Tema del traidor y el héroe", etc.). Piglia y Bolaño parten de ese principio borgeano, y luego, con una ferocidad inusitada en Borges, nos muestran, en iluminaciones frecuentes, cómo ese lector voraz podría ser una clave revolucionaria para otro tipo de vida en la que los cuentos (la máquina del relato) son un arma contra las cuentas (la lógica del dinero). El lector pigliano-bolañero, a veces alucinado y en el delirio, es un héroe y no un cobarde, a veces medio loco o loca, es un profeta, a veces miserable y amargado, sentado en un bar contando sus infortunios de emigrante, es el modelo que se encuentra de una vida que vale la pena vivirse. Y sin embargo, 2666 y El camino de Ida, traicionan esa suerte de fe emancipadora en la lectura con personajes lectores (Archimboldi y Munk) que son "malos modelos", malos maestros del anarquismo literario, contraejemplos del mismo personaje conceptual que convirtió a los dos autores en los grandes maestros de la ficción latinoamericana contemporánea. Insistimos, pues, en que hay una traición narrativa acá. Pero esa traición no debe ser malinterpretada como un juicio valorativo. Es simplemente una movida más en el tablero de ajedrez que adelanta la jugada. Con autores como Piglia (o Bolaño), nos parece que el "formato libro" pide no ser leído de manera aislada, sino en el laberinto de sus innumerables intertextos e intratextos, son libros que son una pieza más en un rompecabezas colectivo, en donde los jugadores (autores y lectores), todos paranoicos pero rigurosamente conectados, juegan a encontrar la teoría de la conspiración que anudará todas las otras. Y para colmo, ¡los jugadores frecuentemente falsifican piezas! 
9 La vocación de la literatura moderna es la especulación activa sobre el mundo que le seguirá al nuestro. La modernidad (Piglia siempre nos decía en clase que la palabra "modernidad" es un eufemismo para evitar la palabra "capitalismo") es, como todo lo humano, finita. Tuvo un origen y tendrá un final. $\mathrm{Y}$ a su fin vendrá otro modo de organización con o sin nosotros, pero que tendrá su semilla en este mundo, son unas formas futuras que ya comenzamos a alucinar desde el principio de la modernidad, viendo paranoicos magos encantadores y genios malignos en Descartes y Cervantes. La literatura entonces se hace el reverso de la historia, con su mirada puesta en el futuro, en un objeto de estudio que todavía no existe en nuestro presente, pero que nos deja pistas ( La ciudad ausente es un ejemplo de este futurismo literario, pero también lo son la escena del joven Hitler encontrándose con Kafka en Respiración artificial, y por supuesto, el ensayo "Teoría del complot").

"El capital", concluía, "ha logrado -como Dios -imponer la creencia en su omnipotencia y su eternidad; somos capaces de aceptar el fin del mundo pero nadie parece capaz de concebir el fin del capitalismo. Hemos terminado por confundir el sistema capitalista con el sistema solar. Nosotros, como Prometeo, estamos dispuestos a aceptar el desafío y asaltar el sol." (Piglia 2013: 160)

"Como Prometeo". El símil en esa cita tan llamativa nos recuerda al subtítulo de la novela de Mary Shelley, Frankenstein or the Modern Prometheus, en la que otro estudiante descubre en su tesis doctoral la clave para hacer nacer el embrión de un mundo nuevo y lo único que logra es crear un monstruo que mata a un montón de gente. La vocación de la literatura es la especulación política. Hay sólo un problema con esa vocación. Es que es una idea tan bella como un encantamiento, un canto de sirena, tan elegante y necesaria como puede ser patética y alienante. Es que cuando le asignamos a la literatura esa tarea de imaginar lo que vendrá después del capitalismo, nada resulta más interesante, nada resulta más imprescindible, todo puede sacrificarse ante ella. Entonces, la literatura se convierte en fe, y como tal, obnubila sus efectos inmediatos, su legitimación presente de ciertos lugares de poder, su indiferencia al sufrimiento que existe ahora, a las vidas que sufren hoy, es decir, la literatura entonces corre el riesgo de convertirse en "mala fe", y esa "mala fe" está muy presente tanto en 2666 como en El camino de Ida. En uno de los momentos centrales de esta novela, los personajes de Renzi y Nina se ponen a analizar literariamente el Manifiesto contra el capitalismo tecnológico de Munk, en particular un pasaje en donde el anarco-terrorista explica la necesidad de matar gente para que se le preste atención a la escritura. En un pasaje que, según Daniel Balderston (2017), es un plagio del manifiesto real del verdadero Unabomber, Munk explica que en el capitalismo contemporáneo, y gracias a los veloces medios de comunicación, cualquier persona puede manifestarse, pero que esa democratización radical de los medios tiene un gran problema: hay demasiados escritores y pocos lectores. No importa qué tan importante sea lo que escribimos, todo se perderá como una gota de agua en un océano de información. Ante este problema, Munk (y el verdadero Unabomber) encontrarán una solución simple: acompañar el texto escrito con el asesinato. La única razón, nos dicen Munk y el Unabomber, por la que hemos llegado a leer su Manifiesto contra el capitalismo tecnológico es porque ha llamado la atención con los asesinatos de esas figuras prominentes de la élite académica americana. Matar consigue lectores. 
La primera vez que oigo algo así, dijo Nina. Matar a "algunas personas" para conseguir lectores. Es un párrafo aterrador. El terrorista como escritor moderno, la acción directa como pacto con el Diablo. Hago el mal en estado puro para mejorar mi pensamiento y expresar ideas que ponen en cuestión a la sociedad entera. La garantía de verdad está dada porque su autor había sido capaz de filtrarse en las redes de control y represión del sistema, realizando decenas de atentados con bombas caseras sin ser localizado durante casi veinte años. (158).

11 La relación entre literatura y mal puro conecta a Munk con el personaje de Carlos Wieder en la novela Estrella distante de Bolaño, y la manera en que es capaz de "filtrarse en las redes de control" nos recuerda a la máquina de Macedonio en La ciudad ausente. Y sin embargo, mientras que en Estrella distante Bolaño ensaya toda una serie de contraejemplos al poeta fascista Wieder y en La ciudad ausente el modo en que la máquina se infiltra en las redes de control termina siendo un modo de afirmar la vida, en El camino de Ida no hay tal alternativa afirmativa. La modalidad asesina de la escritura y la teoría de la lectura de Munk se construyen en la novela como una alegoría crítica de la academia. La universidad americana opera bajo la misma lógica que Munk; construye y justifica su relevancia (y su poder) en una profunda indiferencia hacia la vida. Ésta es la terrible violencia de los hombres educados. Esta cita larga de El camino de Ida, nos parece, sustenta muchos de los argumentos sobre la complicidad de la universidad con la violencia capitalista.

Las clases empezaron a principio de febrero, enseñaba tres horas por semana los lunes a la tarde, en la sala B-6-M de la biblioteca, el seminario tenía una asistencia moderada (seis inscriptos). Era por supuesto un grupo de élite, muy bien entrenado, y mostraba ese aire de conspiración que tienen los estudiantes de doctorado durante los años que pasan juntos mientras escriben sus tesis. Es un tipo de entrenamiento muy extraño que en la Argentina no se conoce. Se parece más bien a un gimnasio del Bronx donde los jóvenes boxeadores son adiestrados por viejos campeones semiretirados que los golpean y les dan órdenes sobre el ring, corriendo siempre el riesgo de terminar en la lona. Me parece uno de los pocos ritos de iniciación que quedan vigentes en el mundo occidental; quizá los conventos medievales tenían ese aire de sigilo, de privilegio y de tedio, porque aquí los estudiantes están casi recluidos, se mueven en un círculo cerrado conviviendo como los sobrevivientes de un naufragio- con sus profesores. Saben que en el mundo exterior a nadie le interesa demasiado la literatura y que son los conservadores críticos de una gloriosa tradición en crisis.

[...] Las universidades han desplazado los guetos como lugares de violencia psíquica. El mismo día en que llegué, un joven assistant professor de una universidad cercana se había atrincherado en su casa en Connecticut y había matado a un policía; permaneció encerrado durante doce horas hasta que llegó el FBI. Exigía que revisaran su promoción a associate porque se la habían rechazado y pensaba que era una injusticia y una desconsideración con sus méritos y sus publicaciones. Lo más divertido fue que al final prometió rendirse si le aseguraban que en la cárcel iba a poder usar armas. Tenía razón, es en la cárcel donde deben usarse las armas, pero se negaron y el joven se suicidó.

Los campus son pacíficos y elegantes, están pensados para dejar afuera la experiencia y las pasiones pero corren por debajo altas olas de cólera subterránea: la terrible violencia de los hombres educados (34-35).

Por supuesto que el narrador acá se equivoca. La universidad no ha desplazado los "ghetos" porque nunca antes la humanidad ha visto tantos inmigrantes desposeídos instalando ghetos, acosados por una violencia física y síquica brutal, como en las últimas dos décadas. Mientas más nos adentramos, más nos parece que El camino de Ida no es una novela sobre este mundo. Es más bien una pesadilla, un infierno, una distopía en la que el capitalismo funciona tan perfectamente bien, tan eficiente e improbablemente, que la 
única violencia que existe es la violencia individual (e individualista) de lectores delirantes y solitarios que encuentran en los libros la ilusión de un "afuera del capitalismo" por el que vale la pena matar.

\section{6}

Los seminarios doctorales que Ricardo Piglia enseñaba en Princeton solían dictarse en el aula B-6-M del sótano de la biblioteca Firestone, y solía haber entre 5 y 10 estudiantes doctorales provenientes, la mayoría, de países latinoamericanos. Recuerdo haber pensado, el primer día del primero de los cuatro seminarios que tomé con Piglia en Princeton, que ese mismo curso enseñado por él en Puerto Rico, Argentina o cualquier país latinoamericano tendría docenas sino cientos de inscriptos (unos años después pensé lo mismo cuando tomé un curso con Alan Pauls en Princeton en donde éramos sólo cuatro estudiantes, Carlos Fonseca, Jeff Lawrence, Ana Sabau y yo), y que el privilegio de esa aula en un sótano en la que una vez a la semana por tres horas teníamos la atención completa de Piglia era un privilegio permitido por algo perverso, por una larga historia colonial entre el norte y el sur del continente americano. Recuerdo también el suicidio del profesor Antonio Calvo, compañero de departamento de Piglia, que es demitido por la universidad en un momento que marca el inicio de una precariedad laboral en la universidad americana tras la crisis económica del 2008. Antonio Calvo pierde su trabajo y es consciente de que nadie está encontrando nuevos puestos, y su suicidio produce un debate intelectual muy pobre (porque todavía, nos parece, no teníamos el lenguaje para entender lo que realmente estaba pasando en la maquinaria neoliberal de la academia) en el que tanto Piglia como el autor de este artículo participan, un debate sobre cómo las instituciones académicas en las que habitamos construyen y justifican su relevancia (y su poder) en una profunda indiferencia hacia la vida común. El suicidio de Antonio Calvo se suma a toda una serie de académicos desesperados durante esos años de "crisis" que recurren a algún tipo de violencia suicida o asesina (el ejemplo de Amy Bishop, profesora de biología en Alabama que asesina a sus compañeros de trabajo, todos hombres, tras serle negado el tenure pasará a formar parte de nuestra segunda novela, Caja de fractales, tras varias conversaciones con Piglia durante esos años). Son víctimas de un sistema jerárquico diseñado para que el único valor que podamos asignarle a nuestra vida consista en el reconocimiento institucional de nuestro trabajo intelectual. Vivir para producir, o perecer. Por más que digamos en este ensayo que El camino de Ida es una novela decepcionante, es capaz de transmitir maravillosamente la desesperación que produce ese sistema de control (saber/poder foucaultiano) que es la academia americana en estos años de necrocapitalismo.

14 Y sin embargo... para una novela que hace un trabajo tan cuidadoso, casi etnográfico, de la universidad americana, nada encontramos en ella sobre las insurgencias de 2011, tan vinculadas a la universidad, que representan la politización y radicalización de toda una generación internacional. Nada encontramos sobre ese momento crucial que marca el verano del 2011 cuando emerge en Nueva York un verdadero movimiento anarquista contra el "capitalismo tecnológico" con el desafiante nombre de Occupy Wall Street ${ }^{7}$. No sorprende que Piglia, que a lo largo de su carrera literaria siempre evitó comentar la política del presente -arguyendo chistosamente que no entiende por qué los periodistas le exigían a un mero escritor que hiciera el trabajo de ellos como periodistas, arguyendo en serio que la política y lo social en la literatura pasan por nudos más lentos- no haya 
escrito sobre esas insurgencias que lo tocaron de cerca a través de sus alumnos en Princeton. En sus novelas, como dijimos al principio, el presente político siempre entra de una manera escondida y cifrada, desde cierta distancia. ¿Cómo se cifra en El camino de Ida la presencia de esas insurgencias como Occupy?

Desde las primeras asambleas de Occupy Wall Street hasta las muchas iteraciones del movimiento durante los años siguientes, encontraremos allí muchísimos académicos de universidades americanas de élite profundamente desencantados con la universidad. Hasta se podría decir que Occupy (y luego el movimiento Black Lives Matter) marca un momento crucial en la historia de la universidad americana que ve a muchos intelectuales finalmente salir de la torre de marfil de la institución posmoderna, un "salir a la calle", un movimiento participativo y de acción directa en donde miles de académicos encuentran, aunque haya sido de manera fugaz, un espacio para la experiencia y la solidaridad en un mundo que es indiferente a ambas cosas. Así como Thomas Munk encuentra una manera de infiltrar los medios masivos y corporativos al acompañar su Manifiesto con asesinatos, Occupy fue un movimiento que también logró infiltrar los medios de comunicación de una manera muy exitosa, no sólo por sus usos creativos de las tecnologías de la información y las redes sociales sino también por su capacidad de crear todo un vocabulario subversivo para atacar los centros financieros de la oligarquía global con un slogan terriblemente efectivo y sucinto: "We are the 99\%". En esa simple frase tan potente tanto por el "nosotros" que construye como por el "ellos" que excluye en ese 1\% restante, y basado en la simple estadística de que el 1\% más rico de Estados Unidos posee más riquezas que el $80 \%$ por ciento más pobre de la sociedad, se cifra un caballo de Troya, una manera efectiva de invadir la velocidad de los medios capitalistas. Estudiantes doctorales que tomaron muchas clases con Piglia y en cuyos comités de tesis Piglia participó activamente y con los que se reunió por incontables horas para hablar de investigación como lo fueron Luis Moreno- Caballud y Jeff Lawrence, y algunos de sus compañeros de trabajo como Susana Draper, fueron figuras que se sumaron con mucho entusiasmo y energía en ese verdadero movimiento anarquista contra el capitalismo tecnológico que fue Occupy. Durante los años en que escribió El camino de Ida, Piglia verá cómo varios de los estudiantes que trabajan sus tesis doctorales con él se radicalizarán políticamente y pasarán a ser figuras importantes de otros movimientos globales muy análogos a Occupy, desde las huelgas en la Universidad de Puerto Rico y en Chile, el inicio de movimientos feministas en Argentina que luego desembocarán en Ni una menos (Cecilia Palmeiro, una de las muchas pensadoras claves del movimiento ${ }^{8}$, escribió una tesis con Piglia durante esos años en Princeton), el 15-M en España, y toda una gama de radicalizaciones que desbordan la universidad posmoderna. Por último, es importante también añadir que hay incontables elementos en la novela de Piglia, incluso párrafos completos y bosquejos de personajes, que Piglia creativamente "plagió" (en el buen sentido anarquista de plagio) de las tesis y novelas de sus alumnos ${ }^{9}$. También fuimos muchos los estudiantes que discutimos con él en un café o en su oficina esos mismos movimientos que lo entusiasmaban. Mientras escribía El camino de Ida, Piglia fue testigo y cómplice (a su manera) de estas radicalizaciones anticapitalistas que buscaban una salida, un camino de ida, de la cárcel de la ciudad letrada. Hay una relación muy tensa, entonces, entre esa novela y esos movimientos. No se trata de que la novela (o su autor) fueran ciegos a esa otra alternativa vista desde la universidad al anarco-terrorismo individualista de Munk. En mayor o menor medida, si tantos de sus alumnos veían y participaban (y siguen participando) en esas insurgencias, se debe precisamente a su influencia sobre ellos, tanto por su pensamiento y su obra como por su maravillosa y original labor docente. 
Entonces, para los lectores obsesivos de la obra de Piglia esta omisión tan sugerente de unos movimientos anti-capitalistas tan cercanos al anarquismo libresco que se discute en su novela, y tan cercanos al espacio de Princeton (a una hora en tren de la ciudad de Nueva York donde comenzó Occupy), no es una casualidad. Pero, ¿cómo lo interpretamos? ¿Es acaso el matemático Thomas Munk, el académico de Harvard y Berkeley que se convierte en asesino de tecnócratas (y de profesoras de literatura) y que escribe su Manifiesto contra el capitalismo tecnológico basándose en libros de Conrad, Tolstoy y Kropotkin, una parodia de movimientos como Occupy? ¿Es un homenaje? ¿Una crítica o un contraejemplo? ¿Será que el ataque a la alianza de las instituciones académicas americanas con Wall Street y el Silicon Valley era más importante o interesante para Renzi que su inverso anticapitalista? ¿Será que tal vez Piglia estaba cifrando en Thomas Munk una moraleja, un riesgo a los problemas teóricos que les tocará afrontar a las próximas generaciones de intelectuales? No estamos tan interesados en contestar estas preguntas. Más bien queremos plantear claramente que la locura solitaria e indiferente a la vida de Thomas Munk que lee mal a la tradición anarquista (y a cierta tradición literaria) para presentar un proyecto "contra el capitalismo tecnológico", contra el mundo financiero y tecnócrata, está conectada de alguna manera a Occupy y al contexto histórico en el que la novela se escribe ${ }^{10}$.

\section{7}

En una entrevista de 1996 para el programa DNI de la televisión pública argentina junto a Matilde Sánchez y Alan Pauls, Piglia, instigado por los dos escritores más jóvenes, se apresura a decir que todo arte es por principio anarquista ${ }^{11}$. Piglia explica que, más allá de las posiciones políticas de los artistas o escritores, la relación entre el arte y el Estado es una relación antagónica. El arte y la literatura representan un universo propio en donde no hay Estado, y en el momento en que toca salir del universo estético, la forma sufre esa invasión del poder; por lo tanto, el arte y la literatura siempre postulan un universo anarquista en conflicto con un poder que siempre ven como externo e invasivo. Y sin embargo, que sea anti-estadista o anarco no implica que este anarquismo literario de Piglia sea individualista (nada más lejano a Piglia que el liberalismo), y en este sentido la estética de Piglia se acerca al anarquismo filosófico de Deleuze y Guattari ${ }^{12}$. Me explico: así como el Estado (en tanto Poder representativo) le resulta antipático al universo estético que exige una libertad radical, también la figura del Autor, del Padre, del Genio, le resulta antipática. Hay pasajes en El camino de Ida donde se discute este problema del individuo dentro del anarquismo y en donde se citan pasajes de Kropotkin en los que éste dice que el individuo no es otra cosa que la ilusión resultante de las fuerzas colectivas de ayuda mutua. Esa idea anti-individualista, traducida a la literatura, explica la defensa y estetización que Piglia hace del plagio, como un modo estético-político de finalmente librarnos de la propiedad intelectual (que es robo, como la propiedad privada), y de abrir la experiencia de lectura paranoica al intertexto infinito.

18 Las diferencias políticas y filosóficas entre el anarquismo y el marxismo abundan. Pero hay una diferencia "literaria", más secreta, más originaria, entre estas dos tradiciones. El materialismo histórico se presenta como ciencia. Su modo predilecto de manifestarse en la literatura es a través de la observación realista. El anarquismo, en cambio, se presenta como deseo ${ }^{13}$. Su modo predilecto de manifestarse en la literatura es la utopía y lo fantástico. La literatura de Piglia tendría que leerse desde esa forma anarquista. 
En sus largas conversaciones sobre anarquismo, el protagonista Emilio Renzi y la profesora de literatura rusa, Nina, llegan a la conclusión de que el modelo revolucionario anticapitalista de Munk no era el del marxismo, tan científico teóricamente como tecnócrata en su práctica, sino la buena vida de la comarca anarquista. Si bien el argumento revolucionario de la buena vida es uno de los más viejos de la tradición anarquista que comienza con William Godwin (el padre de Mary Shelley) y luego con Proudhon, es un argumento igualmente central a las nuevas radicalizaciones feministas, ecologistas y anticapitalistas que siguen creciendo y formulándose con más intensidad en las últimas décadas. Si el socialismo ha sido durante el siglo veinte el concepto que ha elegido la izquierda para confrontar al capitalismo, en esta nueva iteración de la izquierda radical hoy, el concepto antagónico al capital que se ha elegido es precisamente el concepto de "vida". Es un concepto que identifica un cruce muy diverso e interesante de tradiciones: desde los textos académicos de Agamben en la tradición de Foucault, hasta los discursos del austero ex-presidente de Uruguay Pepe Mujica; desde el feminismo radical que se ha convertido en la punta de lanza del movimiento contra el neoliberalismo y que insiste en valorar al cuerpo y darle toda prioridad en nuestra organización social a "cuidar la vida", hasta los movimientos ecologistas radicales que definen el capitalismo como una pulsión de muerte contra la vida misma más allá de lo humano; desde los zapatistas en Chiapas y las naciones nativo-americanas reunidas en Standing Rock protegiendo el agua, hasta los grupos de académicos que han formulado toda una disciplina bajo el concepto de "Antropoceno". El simple concepto de "vida" es un concepto útil y atractivo en el presente porque, por un lado, es desideologizante y por lo tanto es inclusivo de todo un arcoíris de diferencias y radicalidades, y, por el otro lado, establece una clara alianza y cohesión en la manera en que define a un enemigo común (la muerte, un enemigo de todos los humanos, pero también de la naturaleza misma) que es el capital.

En los manuscritos tempranos de El camino de Ida el título de la novela continuaba la larga tradición de Piglia de titular sus novelas con un sustantivo y un adjetivo. El título original era Vidas seriales, un título más pigliano y pertinente, y más cercano a los movimientos anticapitalistas que hemos discutido. ¿Por qué decide Piglia borronear esas "vidas seriales" y titular esta novela "el camino de Ida", y con ese título romper la consistencia de más de diez libros suyos titulados con la misma fórmula? ¿Por qué decide romper esa "serie", sacar la vida, esconderla, y en cambio ponerle un título que no sólo hace un quiebre con su obra sino que también la termina, le da una ida, un fin demasiado cortante, una fuga?

\section{9}

En las especulaciones de Renzi sobre la genealogía ideológica de Munk, el concepto de vida va tomando cada vez más densidad, rebasando el concepto superficial de individuo y convirtiéndose en una fuerza transformadora. No se tratará entonces de cómo pensar la política para vivir mejor, sino de cómo hay que transformar la vida para poder pensar la política. Como nos dice este pasaje sobre la vida de Munk en una cabaña ermita en la desolación de las montañas de Montana: 
Había dividido su vida en secuencias autónomas, que obedecían a la placidez y la quietud de los cambios naturales. La cuestión no era cómo hay que pensar lo que se vive, sino cómo hay que vivir para poder pensar (194). Che Guevara lee todo tipo de libros durante los momentos más peligrosos de su vida revolucionaria. El ensayo abre y cierra con un párrafo de una novela de Jack London que el Che leyera en el Granma. En esos párrafos de la novela de London, nos dice el Che en sus diarios, había aprendido a morir. A lo largo del ensayo Piglia insiste en cómo el Che lee no sólo para aprender a morir leyendo, sino también para aprender a vivir una vida literaria. Nos dice Piglia que la lectura entonces se convierte en un manual ético, leemos para aprender a vivir una vida que valga la pena vivirse. El ejercicio de la lectura (en los personajes de Piglia y de Bolaño) nos hace valientes porque crea valores alternativos al capital y la vida burguesa, valores por los que no sólo vale la pena vivir, sino que también abren la posibilidad de morir con dignidad, valores que rebasan la misma muerte (pensamos acá en las figuras de "Caballeros" en Macedonio Fernández, y en "los valientes" de Bolaño). Esa modalidad ética de la literatura, nos parece, es la gran reformulación que Piglia y Bolaño hacen de "lo borgeano"; la lectura no es una manera de alejarse de la vida sino, por el contrario, de aprender a vivir, la lectura es una pedagogía. La vida entonces deja de ser algo "dado", para convertirse en algo a hacer, un proyecto a construir, la materia prima para una obra de arte.

La figura de Guevara en el ensayo de Piglia (que publica este ensayo cuando ya está escribiendo los borradores de lo que todavía se titulaba Vidas seriales) se parece, curiosamente, a la de Munk: ambos transforman sus vidas a través de la lectura (el primero leyendo a London, el segundo leyendo a Conrad), y cual delirantes Alonsos Quijanos anticapitalistas, toman las armas para anunciar un nuevo mundo. Y en el proceso de transformar la vida, se convierten en personajes conceptuales. Entonces, ¿en qué medida son Munk y Che diferentes en el universo de Piglia? Pues en casi nada y en absolutamente todo, y ahí está el punto. Podríamos decir que la vida del Che, el personaje conceptual "Che Guevara", viene acompañado con un proyecto anti-individualista de sociabilidad y solidaridad con los vulnerables (como se ve al final del ensayo de Piglia), mientras que el personaje conceptual "Munk/Unabomber" es un deseo solitario e individualista de destrucción. La diferencia, pues, es que mientras el Che se construye como modelo ético en El último lector, Munk se construye como contraejemplo, como una suerte de advertencia sobre los riesgos y peligros de ese tipo de lectura voraz que transforma la vida. Che Guevara es "el último lector" (la obra de Piglia está llena de personajes que son el "último" de algo, como comenta Alan Pauls ${ }^{14}$ ), es una modalidad de lectura ética que parece venir de un mundo anterior que ya ha pasado de moda y persiste en el presente como ruina (y como posibilidad revolucionaria). La figura del Che como lector es emocionante porque desencaja la lectura de la prisión de la ciudad letrada y de pronto estamos leyendo en las trincheras de una guerrilla en Cuba o en el Congo o en Bolivia. El lector deja de ser un ser solitario encerrado en la biblioteca. Munk es la caricatura de ese "último lector", su agonía o farsa; lee, transforma su vida para poder pensar contra el capitalismo, pero tan sólo sale de la cárcel de la universidad para crearse otra cárcel privada en la montaña. El emocionante poder transformador de la lectura es invertido en construirse otra cárcel de la experiencia: primero en la universidad/cárcel, luego en la cabaña ermita, luego en la verdadera cárcel a donde Renzi lo va a visitar. En ese sentido, podemos decir que El camino de Ida es una novela con moraleja, lo que se dice 
en inglés un "cautionary tale", una advertencia del buen maestro sobre los riesgos que les esperan a los que sigan sus pasos.

\section{0} joven y partes de la trama son plagiadas en su propia novela corta Prisión perpetua. The Lesson of the Master cuenta, como Prisión perpetua, la historia de un joven escritor y su relación con un escritor viejo y famoso a quien el joven admira. Pero pronto la admiración se convierte en recelo, y la gran "lección del maestro" es la manera de la traición. Es una novela sobre el costo que le cobra el arte a la vida. En la novela de James, el viejo escritor se percata de que el escritor joven se está enamorando de una hermosa joven lectora, admiradora de ambos. Entonces, le aconseja al joven escritor que se vaya a viajar y evite a toda costa enamorarse ya que la felicidad (la buena vida) destruiría su arte. Cuando el joven escritor vuelve de sus viajes, infeliz, pero habiendo escrito sus mejores páginas, descubrirá dolorosamente que el viejo escritor se ha casado con la lectora de la cual el joven se había enamorado y a la que había abandonado debido a los consejos de su maestro. El joven escritor confronta al viejo tras su traición, y el master le dice, con una ironía ambigua para el lector, que se casó con la joven lectora supuestamente para proteger al joven escritor de los peligros de la felicidad. Piglia copia creativamente la trama principal de esa novela en Prisión perpetua, siendo Emilio Renzi el aprendiz de escritor y el gringo viejo Steve Ratliff el viejo traidor.

Nos dice Alan Pauls que la figura del "último" en Piglia a veces viene acompañada de otra figura recurrente en su obra: la del traidor.

De ahí, también, el parentesco perturbador que hay entre la figura del último y la del traidor, otro gran habitué del mundo Piglia. El traidor, es decir: el que parece incluido en un mundo, un mundo que dice representar, al que dice adherir, y de golpe, con una palabra, o un acto, o una palabra que suena y es eficaz como un acto, hace pasar de un lado a otro algo que no debería pasar, o pega el salto y se alista de lleno en el mundo enemigo. En Piglia, el último y el traidor son a veces la misma figura. Según una dinámica que no deja de ser pedagógica, ambos aseguran un pasaje, una transmisión, un legado: papeles, documentos secretos, fetiches personales que encierran la clave de una vida... Lo que está en juego es siempre algo que queda, un resto acorralado por un dilema fatídico: conservarse y consumirse o cambiar de mano y sobrevivir (2017: 276).

El camino de Ida es la última novela de Piglia y como tal, es una novela traidora. Traiciona la tradición anarquista del autor. Traiciona el presente histórico en el que se escribe a punto tal que a veces el autor parece burlarse de sus propios cómplices intelectuales y sus alumnos. Traiciona su poética ${ }^{15}$. Traiciona y ridiculiza la figura central de su obra que es el lector paranoico; el letrado que encuentra en el delirio una iluminación es remplazado por un letrado delirante vaciado de cualquier iluminación. Es una invitación a rechazar todo lo que hemos aprendido en el resto de su obra. Incluso podemos ir más allá, y decir que El camino de Ida es la despedida de toda una modalidad literaria de la que Piglia y Bolaño son las últimas expresiones: la novela de culto al autor. Quizás, pues, esta novela sobre el individualismo del letrado es la manera que encuentra la obra de Piglia de finalmente deshacerse del culto al autor y abrir el camino para un verdadero anarquismo literario en el cual un autor colectivo, un "cualquiera", como otro alumno de Piglia 
planteará ${ }^{16}$, logrará articular una forma que finalmente tomará el sol, y nos mostrará una forma en donde, como deseaba Macedonio, el amor no será interrumpido por la muerte.

\section{BIBLIOGRAFÍA}

Avelar Idelber, Alegorías de la derrota: la ficción postdictatorial y el trabajo de duelo, Santiago de Chile, Editorial Cuarto Propio, 2000.

Balderston Daniel, "Piglia y el Unabomber: Literatura y política en El camino de Ida", Revista Landa, vol. 5, n² 2, 2017, p. 378-391.

Bolaño Roberto, Estrella distante, Barcelona, Anagrama, 1996.

--- 2666, Barcelona, Anagrama, 2004.

Carrillo Francisco, Excepción Bolaño: Crisis política y reescritura de la derrota, San Juan de Puerto Rico, Instituto de Cultura Puertorriqueña, 2014.

Fonseca Carlos, Coronel Lágrimas, Barcelona, Anagrama, 2015.

Lawrence Jeff, "The international roots of the $99 \%$ and the "politics of anyone", IC-Revista Científica de Información y Comunicación n 10, Universidad de Sevilla, 2013, p. 53 - 72.

Moreno-Caballud Luis, Culturas de cualquiera: Estudios sobre democratización cultural en la crisis del neoliberalismo español, Boadilla del Monte (Madrid), Acuarela, 2017.

Palmeiro Cecilia, "The Latin American green tide: Desire and feminist transversality", Journal of Latin American Cultural Studies. Interventions and notes from the field, August 6, 2018. Web.

Pauls Alan, "Last but not least", Revista Landa, vol. 5, nº 2, 2017, p. 273-279.

Pauls Alan y Matilde Sánchez, "Delirio y Poder”. Entrevista a Ricardo Piglia, DNI Incidentes, Canal 7, Televisión Pública Argentina, año 1995-1996.

Piglia Ricardo, La ciudad ausente, Barcelona, Seix Barral, 1995.

--- El último lector, Barcelona, Anagrama, 2005.

--- "Nuevas tesis sobre el cuento", Formas breves, Barcelona, Anagrama, 2006.

--- Prisión perpetua, Barcelona, Anagrama, 2007.

--- El camino de Ida, Barcelona, Anagrama, 2013.

Piglia Ricardo y Roberto Bolaño, “Conversación electrónica entre Piglia y Bolaño”, Babelia, El País, 3 de marzo de 2001.

Prieto Julio, De la sombrología: Seis ensayos en busca de Macedonio Fernández, Madrid, Iberoamericana, 2010.

Reszler André, La estética anarquista, Buenos Aires, Libros de la Araucaria, 2005.

Rosa Luis Othoniel, Comienzos para una estética anarquista: Borges con Macedonio, Santiago de Chile, Editorial Cuarto Propio, 2016.

--- Caja de fractales, Buenos Aires, Entropía, 2017. 
Valencia Sayak, Capitalismo gore, Tenerife, Melusina, 2010.

Anexo bibliográfico: Tesis doctorales en las que Ricardo Piglia participó como director o lector en Princeton

Dieleke Edgardo, Donde habita lo real. Los límites entre ficción y no ficción en el cine y la narrativa latinoamericana contemporánea. (2013)

García Liendo Javier, Culturas de masas alternativas: intelectuales, tecnología y comunicación en Ángel Rama y José María Arguedas. (2010)

Fonseca Carlos, States of Nature: Catastrophe, History and the Reconstruction of Spanish America. (2014)

Fromm Aurora Rebecca, Erkennbarkeit. La Huella de Walter Benjamín en América Latina. (en curso)

Hernández-Castellanos Camilo, Los teatros de la muerte. Ficciones del cadáver en la modernidad ( Colombia y México 1930-1960). (2013)

Lawrence Jeffrey, The Experience and the Reader in the Twentieth-Century Literatures of the Americas. (2014)

Moreno-Caballud Luis, Topos, carnavales y vecinos. Derivas de lo rural en la literatura y el cine de la transición española (1973-1986). (2010)

Padilla Jose-Ignacio, Materia y significación en las poéticas latinoamericanas del siglo XX: Vanguardias, Noigandres y Jorge Eduardo Eielson. (2008)

Palmeiro Cecilia, Para ser bella hay que sufrir: escrituras y prácticas entre Argentina y Brasil. (2009)

Rivera Díaz Fernando, Escritura envenenada y novela de la traducción: la poética novelística en El zorro de arriba y el zorro de abajo de José María Arguedas. (2006)

Rosa Luis Othoniel, Anarquismos Literarios: Borges con Macedonio. (2012)

Sabau Ana, Revoluciones y revelaciones: una arqueología de la imaginación política del siglo XIX en México . (2014)

Sendra Ferrer Olga, Barcelona (1950-1976): ciudad de márgenes. La construcción de la ciudad condal a través de la narrativa y la fotografía de posguerra. (2012)

Stephanis Rebecca, From Resurrection to Recognition: Argentina's Misiones Province and the National Imaginary. (2008)

Valenzuela Andrea, Roberto Bolaño, la ironía y sus precursores. (2008)

\section{NOTAS}

1. A lo largo de este artículo hacemos referencia a varios de los textos académicos, tesis y novelas de los estudiantes doctorales de Piglia en Princeton, así como a su participación en movimientos políticos. Por esto, además de los textos mencionados en la bibliografía, hemos querido incluir también un anexo con una lista de tesis doctorales en las que Piglia participó como director o evaluador. En los títulos de esas tesis está el intertexto secreto de El camino de Ida.

2. Daniel Balderston es, hasta ahora, el único otro crítico que ha visto una conexión entre $E l$ camino de Ida y el surgimiento de una nueva radicalidad política en los movimientos contemporáneos. Balderston (2017) ve esa conexión en la insistencia en "los mundos posibles". A pesar de que no profundiza en este aspecto, identifica un conflicto entre la novela y esos movimientos por "otros mundos posibles", ya que la novela insiste en formas arcaicas y nostálgicas que no se identifican con esos movimientos. 
3. Jeff Lawrence, uno de los alumnos doctorales de Piglia en Princeton, estará escribiendo durante los mismos años en que Piglia escribe El camino de Ida un libro titulado Anxieties of Experience: The Literatures of the Americans from Whitman to Bolaño en donde argumenta que las novelas de Piglia y Bolaño representan la confluencia de dos tradiciones en conflicto: por un lado, la literatura americana de la experiencia y por el otro, la literatura latinoamericana del lector voraz. El camino de Ida es un intento de unir estas dos tradiciones.

4. Tomamos este concepto del libro de la teórica tijuanense Sayak Valencia Capitalismo gore (2010) en donde, influenciada por el feminismo radical y cierto vocabulario del ecologismo, utiliza el concepto de "necrocapitalismo" para conceptualizar la manera en que el capitalismo mercadea en muerte, tanto por la violencia directa que genera (el narcotráfico, el tráfico humano, los feminicidios y la destrucción ecológíca) como por su sustento en una violencia estructural clasista y racista.

5. Uno de los seminarios más famosos de Piglia se titulará, precisamente, "Ficciones Paranoicas".

6. Para un estudio detallado sobre los efectos del posmodernismo en la intelectualidad latinoamericana y en particular en La ciudad ausente de Piglia, ver Idelber Avelar, Alegorías de la derrota (2000).

7. Ver Jeff Lawrence: "The international roots of the $99 \%$ and "the politics of anyone" " (2013), uno de los artículos tempranos sobre Occupy en el que uno de los estudiantes de Piglia documenta la importancia de los inmigrantes puertorriqueños, griegos y españoles (entre muchos otros) que conformaron ese movimiento en Estados Unidos y que, en gran medida, llegaron allí a través de la universidad americana.

8. Ver Cecilia Palmeiro 2018.

9. Por ejemplo, otro matemático ermitaño, el protagonista de la novela de Carlos Fonseca Coronel Lágrimos, que Fonseca escribió junto a Piglia (Piglia era muy generoso leyendo no sólo los textos académicos sino también los textos literarios de sus alumnos), recuerda mucho a Munk.

10. También nos parece que la insistencia de la novela en la ironía (a la que por momentos se defiende y por momentos se acusa) problematiza la relación con estos movimientos anticapitalistas en el presente. Tanto Balderston como Raquel Cobo identifican la importante relación entre ironía y política en la novela. Balderston (2017), sin embargo, señala también la ironía como un problema, ya que si por momentos la novela esboza un llamado a la acción, a ir de lo literario a lo político, la ironía con la que aborda al personaje de Munk (que no es para nada un ejemplo de acción política efectiva) es paralizante. Balderston insiste en la importancia de la ironía para evitar la lectura utilitaria, pero es consciente, como nos dice el estudioso de Macedonio Fernández, Julio Prieto, que "la ironía es conservadora, el humor revolucionario" (Prieto 2010: 71-72).

11. Es muy interesante cómo la entrevistadora y escritora Matilde Sánchez arrincona a Piglia para ver si es posible que en su teoría de la ficción haya alguna forma de poder o alguna forma de Estado que sea positiva, quizá intentando encontrar en Piglia alguna posible mínima alianza con el peronismo estatista del que siempre vivió tan cerca, pero al que nunca se unió del todo precisamente por su anti-estatismo que le venía de la misma tradición anarquista de Macedonio Fernández y de Roberto Arlt (por no decir de Malatesta, de Gramsci, de Deleuze, de Guattari o del mismísimo Kropotkin).

12. La gran aventura filosófica que es la obra de Deleuze y Guattari consiste en cruzar la idea anarquista del individuo como resultante (series y segmentos) con el sicoanálisis. Según ellos, Freud reducía el inconsciente al universo familiar, a la familia burguesa como origen y núcleo de todos los traumas, y por lo tanto Freud está ciego ante las series y segmentos sociales que traspasan el espacio individual/familiar, y se transvasan como deseos colectivos. 
13. "La estética anarquista se vuelve resueltamente hacia el porvenir, hacia lo desconocido. Contribuye, así, poderosamente, a la eclosión de la cultura moderna. La estética marxista no dirige su mirada lejos. Se contenta con regentar o interpretar lo real; pone la obra que existe en relación con la situación económica, social y política de la sociedad para deducir su significado social. [...] La estética marxista recuerda incansablemente al escritor, al artista, su responsabilidad social. Lo invita a tomar parte en los grandes debates sociales, políticos, filosóficos de la época. Lo conmina a bajar a la arena, a comprometerse. La estética anarquista ve en la creación artística las realizaciones generales del hombre sublevado. Animándolo a liberarse del peso de la tradición, desempeña respecto del artista una acción liberadora más acusada, pero también, y sobre todo, una función creadora. Lo impulsa a buscar caminos siempre renovados de la creación. La estética marxista se presenta como guardián de la tradición realista. La estética anarquista es el guardián del espíritu de ruptura. Y puesto que tiene la mirada fija en el porvenir -la utopía- interpreta tal vez mejor la aspiración del artista de hoy a la libre expresión de su fe de herético." (Reszler 2005: 133)

14. "Salvando las distancias de escala mítica, envergadura histórica y reverberación pop que las separan del Che Guevara, todas las figuras de últimos que deambulan por el mundo de Piglia responden de algún modo a la tipología instituida por el último lector. El detective como "último intelectual", Borges como "el último escritor del siglo XIX", Tardewski [Gombrowicz] como último avatar del europeo trasplantado en Argentina, el último narrador oral, el último oyente... Difícil dar un paso por Piglia sin tropezar con estos emisarios de una patria y una ética que agonizan, gente pasada de moda, "últimos sobrevivientes", como se lee en Respiración artificial, “de una estirpe en disolución” " (Pauls 2017: 274).

15. Balderston (2017) también identifica en la novela la insistencia irónica de exigir con urgencia que se entiendan tanto los relatos como las acciones políticas que allí se narran y, a la vez, frustrar los intentos de comprensión.

16. Uno de los alumnos de Piglia, Luis Moreno- Caballud, escribirá durante esos años un libro muy potente y muy marcado por la obra del maestro titulado Culturas de cualquiera (2017), que es una aventura filosófica a histórica sobre cómo ciertos modos de producción cultural al margen tanto del mercado como de las instituciones del saber y de "los expertos" tecnócratas pueden construir un frente plural anticapitalista. Las salidas que Piglia nos niega en El camino de Ida, Luis Moreno nos las muestra sin afán de creatividad artística en ese libro tan importante cuyos manuscritos Piglia leyó y comentó.

\section{RESÚMENES}

El ensayo sostiene que la novela El camino de Ida traiciona la gran empresa de la obra de Piglia, el intento de recrearle un aura politizada a la figura borgeana del lector paranoico. El artículo profundiza la marcada influencia que ejercen tanto el contexto histórico en que se escribe la novela (los acontecimientos del 11 de septiembre de 2001, la crisis económica del 2008 y el surgimiento del movimiento Occupy Wall Street), cuanto el anarquismo presente en la obra del autor, así como los proyectos de los alumnos de Piglia en Princeton durante estos años, que serán aludidos de manera secreta en el texto novelístico. 
Cet essai soutient que le roman El camino de Ida trahit la plus grande innovation de l'œuvre de Piglia, à savoir, l'effort de recréer une aura politique au modèle borgésien du lecteur paranoïaque. L'article contient une étude en profondeur des trois influences principales qui affectent le roman: le contexte historique de sa rédaction (les événements du 11 septembre de 2001, la crise économique de 2008 et l'émergence du mouvement Occupy Wall Street), la présence de l'anarchisme dans l'œuvre entière de l'écrivain et enfin les nombreuses dissertations et projets académiques des étudiants de Piglia à Princeton, auxquels El camino de Ida fait secrètement allusion.

This essay argues that the novel El camino de Ida betrays the greatest innovation of Piglia's work, that is, to recreate a political "aura" to the Borgesian figure of the paranoid reader. The article is an in-depth study of three main influences in the novel: the historical context in which it is written (the events on 11 september 2001, the economic crisis of 2008 and the emergence of the Occupy Wall St. movement), the traces of anarchism readable in the entire work of the writer, and the many dissertations and book projects of Piglia's students in Princeton that are secretly alluded to in El camino de Ida.

\section{ÍNDICE}

Palabras claves: anarquismo, Occupy, Princeton, novela, Latinoamérica

Mots-clés: anarchisme, Occupy, Princeton, roman, Amérique Latine

Keywords: anarchism, Occupy, Princeton, novel, Latin America

\section{AUTOR}

\section{LUIS OTHONIEL ROSA}

University of Nebraska

luisothoniel@gmail.com 